M. J. Kirkman and W. L. Godfrey

Operations Support Engineering Department Atlantic Richfield Hanford Company Richland, Washington

For presentation at the 66 th National Meeting of the American Institute of Chemical Engineers, Portland, Oregon, August $24-27,1969$

August 4, 1969

Work performed under Contract AT (45-1) -2130 between the Atomic Energy Commission and Atlantic Richfield Hanford Company

This report was prepared as an account of work sponsored by the United States Government. Neither the United States nor the United States Atomic Energy Commission, nor any of their employees, nor any of their contractors, subcontractors, or their employees, makes any warranty, express or implied, or assumes any legal liability or responsibility for the accuracy, completeness or usefulness of any information, apparatus, product or process disclosed, or represents that its use would not infringe privately owned rights. 


\section{DISCLAIMER}

This report was prepared as an account of work sponsored by an agency of the United States Government. Neither the United States Government nor any agency Thereof, nor any of their employees, makes any warranty, express or implied, or assumes any legal liability or responsibility for the accuracy, completeness, or usefulness of any information, apparatus, product, or process disclosed, or represents that its use would not infringe privately owned rights. Reference herein to any specific commercial product, process, or service by trade name, trademark, manufacturer, or otherwise does not necessarily constitute or imply its endorsement, recommendation, or favoring by the United States Government or any agency thereof. The views and opinions of authors expressed herein do not necessarily state or reflect those of the United States Government or any agency thereof. 


\section{DISCLAIMER}

Portions of this document may be illegible in electronic image products. Images are produced from the best available original document. 


\title{
TREATMENT OF LIQUID WASTES BY EVAPORATION TO SALT CAKES.
}

\author{
M. J. Kirkman and W. L. Godfrey \\ Atlantic Richfield Hanford Company \\ Richland, Washington
}

\section{INTRODUCTION}

In the atomic energy industry, radioactive wastes are not disposed of per se, but are stored in forms which are isolated from the biosphere. Radioactive wastes from fuel reprocessing plants, which comprise the majority of wastes handled, have been stored on an interim basis as solutions in underground tanks while long-term storage methods are being developed. Work is continuing on improving the present interim stcrage methods to further increase the certainty of safely confining radioactive materials.

Work began several years ago at Hanford to develop processes for converting liquid wastes presently stored in underground tanks to solids which could then be stored in the same underground tanks. The process, referred to as In-Tank Solidification (ITS), greatly reduces the volumes of stored waste thereby eliminating the need for additional tank space in the near future. The process also immobilizes radionuclides in a matrix which prevents migration to the underlying soil even if the tanks should lose their structural integrity in the future. This paper outlines methods employed for evaporating radioactive waste solutions to a minimum volume as salt cakes. 
SUMMARY

The ITS Program has proven to be an effective method for treating the liquid wastes at Hanford. All liquid wastes currently stored will be eventually converted to salt cake. In this form, the radionuclides in the wastes will be immobilized and can be safely stored with minimum surveillance.

\section{ITS DEVEIOPMENT}

Evaporation has been used routinely in the atomic energy industry to reduce the volumes of waste which must be stored. The maximun concentration that could be achieved, however, was limited to avoid solids formation which would cause concentrate transfer problems in long underground pipelines.

Two evaporation processes were developed for filling underground storage tanks with solids. With one process, waste-solutions were highly concentrated within an underground tank and then allowed to solidify upon cooling. Laboratory and pilot plant demonstrations of the process were successful; hovever, a production scale demonstration of the process was only partially successful because the waste dia not unifomly contain sufficient hydrate forming salts to combine with all the residual liquid when the concentrate cooled.

In the second process, vastes were continuously concentrated and then cooled in a nearby underground tank where salt crystalIized and deposited. The cooled, clarified supernatant was pumped from the crystallizer tank, mixed with fresh feed, and recycled back 
to the evaporator for further concentration. The process was continued until the crystallizer tank filled with salt cake. This technique was successfully demonstrated and is now being used.

\section{ITS PROGRAM}

Large quantities of liquid radioactive wastes generated during chemical processing of irradiated nuclear fuel at Hanford are stored as alkaline slurries in underground, steel-lined, reinforced concrete, tanks with capacities from 500,000 to 1,000,000 gallons. From the results of the ITS demonstration program, it was determined that the most economical and flexible method for solidifying wastes was a concentration-crystallization process in which large underground tanks were used as process vessels.

Waste solutions are concentrated in an evaporator until crystallization begins at the boiling temperature. The resulting.slurry is transferred to underground "crystallizer" storage tanks where solids in the slurry, together with crystals which form as a result of cooling, deposjt. Cooled supernatant is mixed with fresh feed and is recycled to the evaporator for further concentration. Solids deposit as wet sludges in the crystallizer tanks until the tanks are essentially filled. The small volume residual supernatant is then pumped out, and the sludges are dried.

Three different evaporator facilities are presently concentrating radicactive waste solutions to salt cakes: a hot air sparger evaporator, a steam heated evaporator, and an electrical immersion heater evaporator. 
The air sparger evaporator and the steam heated evaporator are first generation approaches, and the electric immersion heater is a second generation Iacility designed to take advantage of more recently developed technology. The air sparger evaporator has been described in detail elsewhere $(1)$ and will be discussed only briefly here. The steam heated evaporator is more or less standard equipment in the chemical processing industry and will also be discussed only briefly. The electric immersion heater evaporator, however, is a truly unique facility and will be discussed in greater depth.

\section{HOT AIR SPARGER EVAPORATOR}

The hot air sparger evaporator consists of a portable electric air heater installed above ground and an annular air sparger installed within a 750,000-gallon underground waste storage tank which has been modified to serve as an evaporator vessel. Equipment to treat the off-gas from the tank includes a scrubber, a deentrainer, a condenser, a blower, and a filter.

Figure $I$ is a schematic diagram of the sparger evaporator. Air is heated to about $1200 \mathrm{~F}$ and sparged into the waste solution at a rate of about 3000 standard cubic feet per minute. Since entrainment in the off-gas is directly related to the temperature of air entering the solution(2), about half of the input energy is transferred to the solution through the specially designed sparger and the air enters the solution at temperatures below $700 \mathrm{~F}$. The sparger also serves as an airlift circulator that generates liquid flow rates 
FIGURE I

HOT ATR SPARGER EVAPORATOR

SCHESATIC DIAGPAY

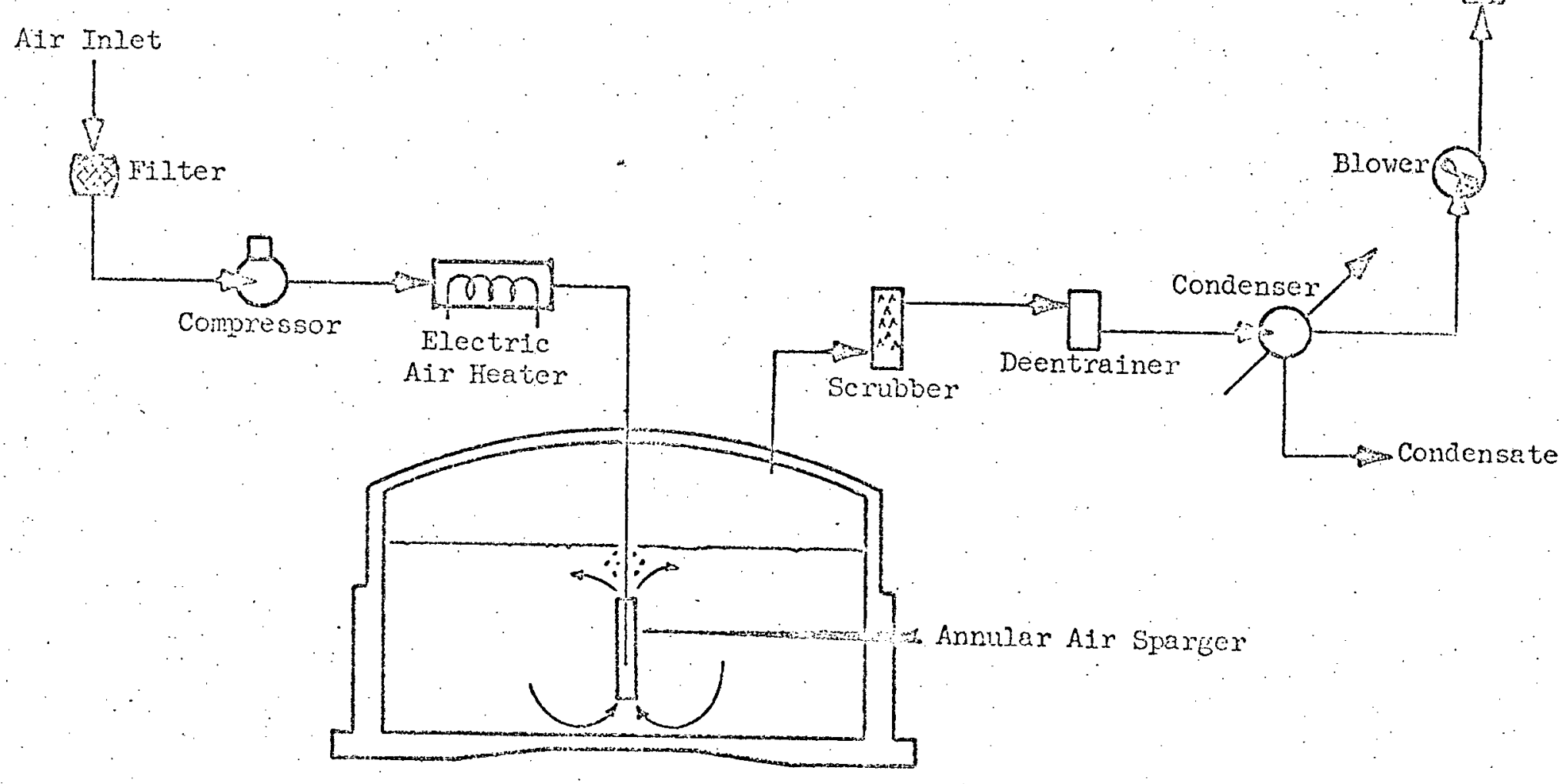


estimated at 10,000 gallons per minute (gpm) through the sparger annulus. The high liquid flow rates provide turbulence to ensure intimate air-liquid contact, and agitation to mix the tank's contents.

An airlift circulator is essentially a submerged vertical pipe which is open at both ends. Air discharged at the pipe bottom reduces the density of the solution in the pipe with respect to the surrounding liquid and the density difference results in a hydraulic head sufficient to generate high liquid flow rates with relatively small air flow rates. Since the circulator contains no moving parts, its operation is essentially maintenance free.

Humid air drawn from the tank vapor space is scrubbed and passed through a deentrainer(3). The cleaned air is then cooled to condense water vapor, and is exhausted to the atmosphere after passing through a bank of high efficiency filters that remove essentially all particulate material.

Waste solution is pumped to the evaporator tank as the process contimes until the tank's contents reach a predetermined concentration. The concentrate is then pumped to another tank for cooling and solids deposition. The concentrator tank is refilled with fresh waste solution and the cycle is repeated. About 700,000 gallons of waste are evaporated during each four-month cycle.

A1l of the equipnent at the facility that requires routine maintenance is installea above ground and is readily accessible. The above-ground off-gas equipment becomes internaliy contaminated. 
during operation, but water or chemical solution flushes satisfactorily decrease the radiation levels so that maintenance can be performed within routine radiation control work procedures.

- The air sparger evaporator has a demonstrated boil-off capacity of 5 to $7 \mathrm{gpm}$. Since the facility was started up in March, 1965, approximately 5.5 million gallons of water have been evaporated and about one million gallons of salt cake have been produced.

\section{STEAM HEATED EVAPORATOR}

The steam heated evaporator is a conventional short tube thermosiphon evaporator installed in a shielded concrete structure that protects operating personnel from radiation emitted by the wastes. Vapor treating equipment, a deentrainer and a cyclone separator, are also installed in the shielded building and a condenser and condensate catch tank are located in an adjacent facility. Whenever maintenance is needed on the equipment that contacts the waste solution, chemical flushes are used to reduce radiation fields sufficiently to permit contact maintenance.

Figure II is a schematic diagram of the steam heated evaporator. Waste solution is pumped continuously from a 750,000 -gallon feed tank to the II,000-gallon evaporator vessel and concentrated. Prior to being condensed, overhead vapor is passed through a cycione separator and a wire mesh deentrainer to remove entrained waste droplets. Evaporator bottoms are continuousiy discharged to an underground storage tank cascade for cooling and salt deposition. 


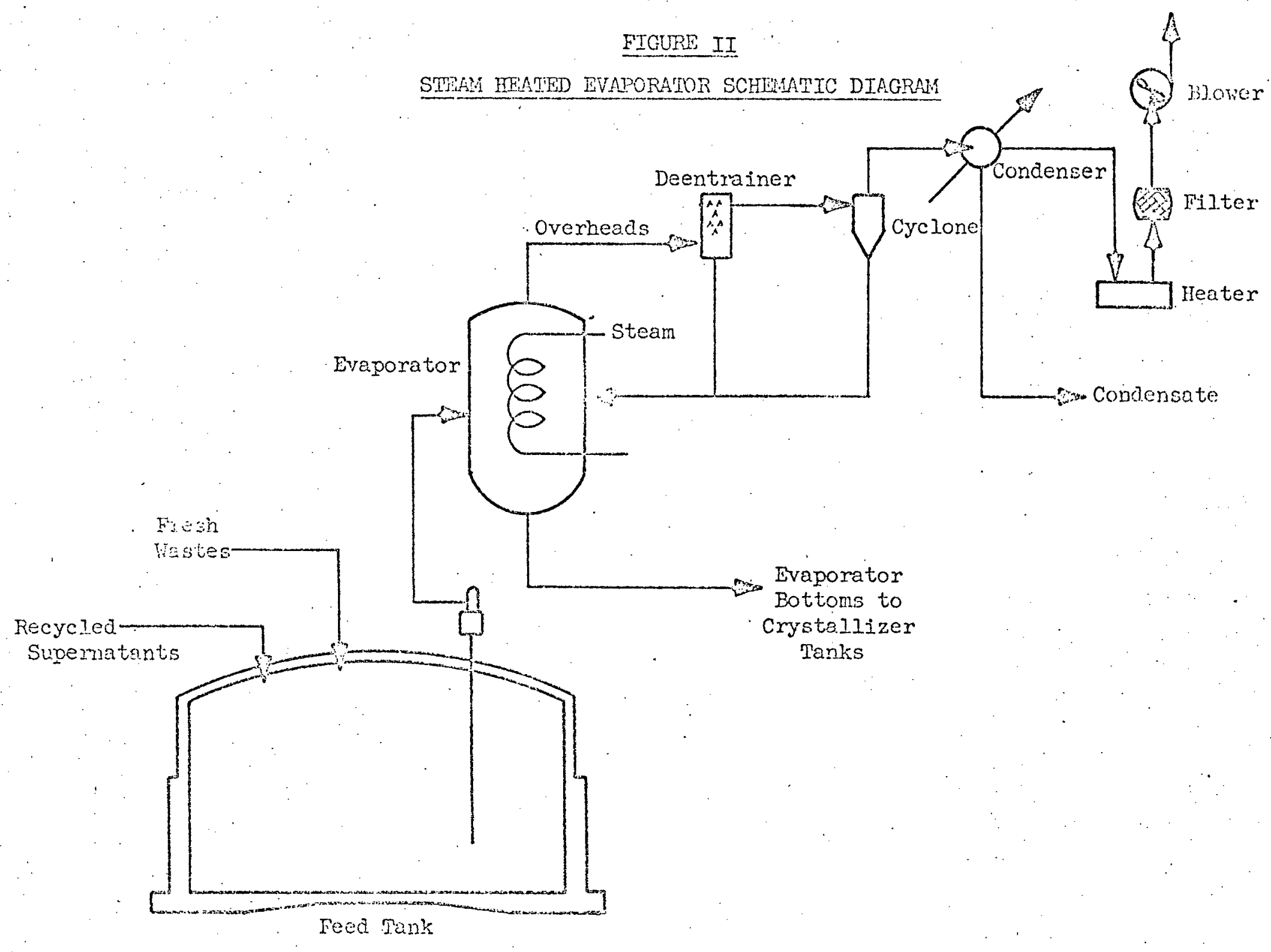


The underground tanks which receive the hot concentrated evaporator bottoms are cooled by air purging the tanks' vapor spaces which causes the concentrate to cool in the same manner as liquids in cooling ponds, i.e., evaporation and sensible heat transfer to. the purge air. Water vapor removed from the tanks with the purge air also effectively increases the evaporation rate obtained by the facility. The tank cooling system is shown in Figure III. Atmospheric air is drawn through the tank vapor spaces by a heater-filterblower assembly that serves several tanks. The humidified air that is drawn from the tanks is heated above its dev point, is passed through high efficiency filters, and is exhausted to the atmosphere. The steam heated evaporator has a demonstrated boil-off capacity of 11 to 13 gorn.

Since the facility was started up in January, 1956, approximately 9 million gallons of water have been evaporated and 1.5 . million gallons of salt cake have been produced.

EIECTRIC TMMERSIOIN HEATER EVAPORATOR

The electric immersion heater evaporator consists of a fourmillion watt electric immersion heater - installed in a 750,000 gallon underground waste storage tank which has been nodified to serve as an evaporator vessel. All equipment requiring routine maintenance is installed above ground and is readily accessible. Ofi-gas equipment wich becomes intemally contaminated during operation is satisfactorily cleaned by water or chemical solution flushing. 
FIGUER III

CRYSTALLIZER TAMK SCHMATIC

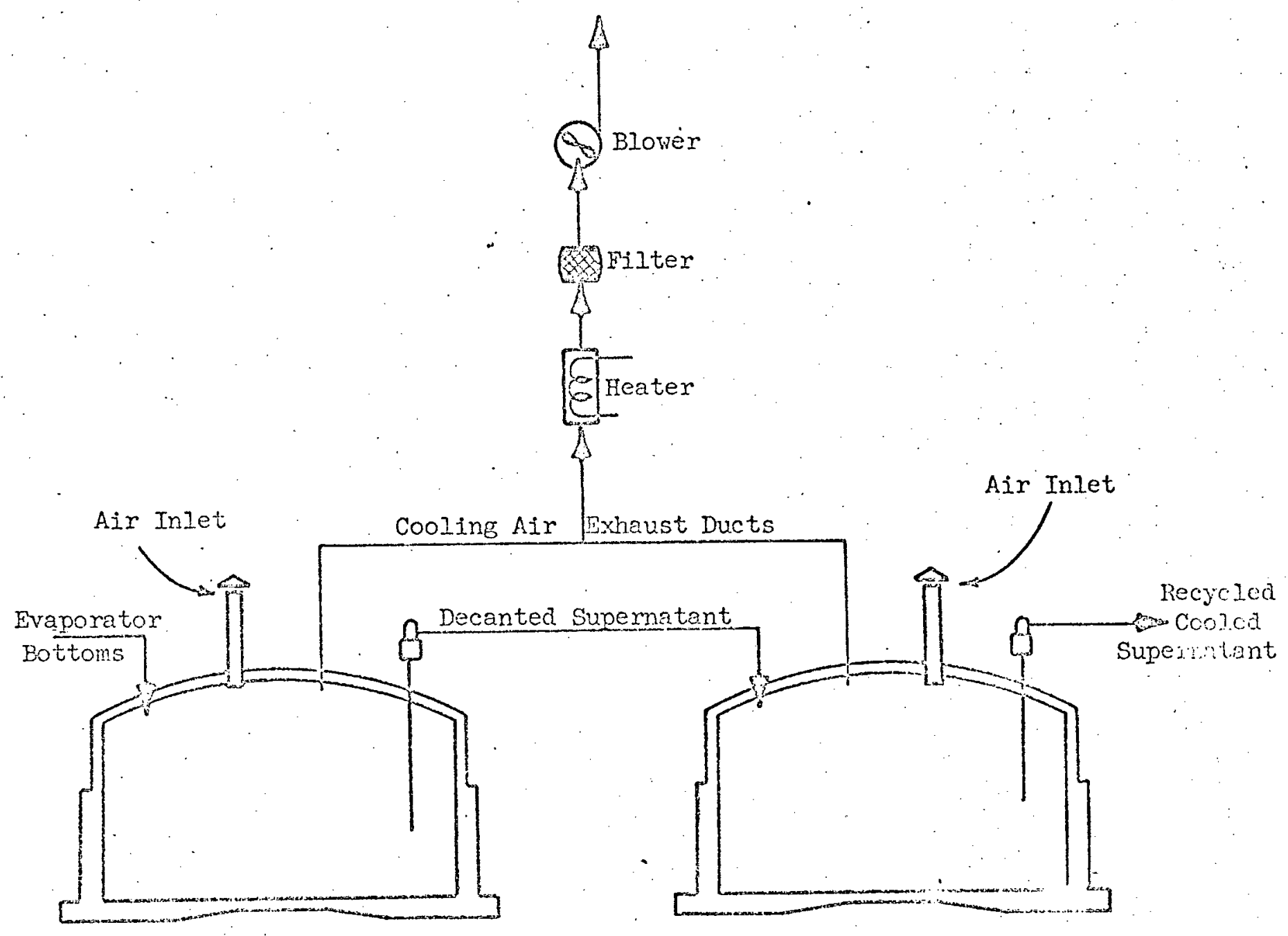


Figure IV is a schematic diagram of the electric immersion heater evaporator facility. Waste solution is pumped from a feed tank to the evaporator tank and concentrated. Water vapor is draw from the evaporator vessel vapor space which serves as a deentrainer chamber for waste solution droplets, is passed through a wire mesh deentrainer, and is condensed. Noncondensibles are drawn from the condenser, heated above their dew point, filtered through high efficiency filters, and discharged to the atmosphere. Demonstrated boil-ofi capacity for the facility is 12 to $14 \mathrm{gpm}$.

Concentrated waste solutions are continuously pumped from the concentrator tank to a cascade of underground storage tanks for cooling and salt deposition in the same manner as previously described.

The electric immersion heater consists of four quadrants. that are rated at one million watts each. Quadrant construction was chosen to facilitate heater fabrication, transportation, installation, and maintenance. Four floating delta transformers supply 480-volt, 3-phase power to the heater quadrants, and each quadrant is operated independently to provide operating and maintenance flexibility. Each quadrant is an assembiy of 90 hairpin-shaped low watt density heating elements (Figure V) which are $1 / 2$-inch in diameter and 39 feet long; only the lower 13 ieet of the hairpin section, however, comprises the heated region. The four heater quadrants are installed inside a single 40 -inch 

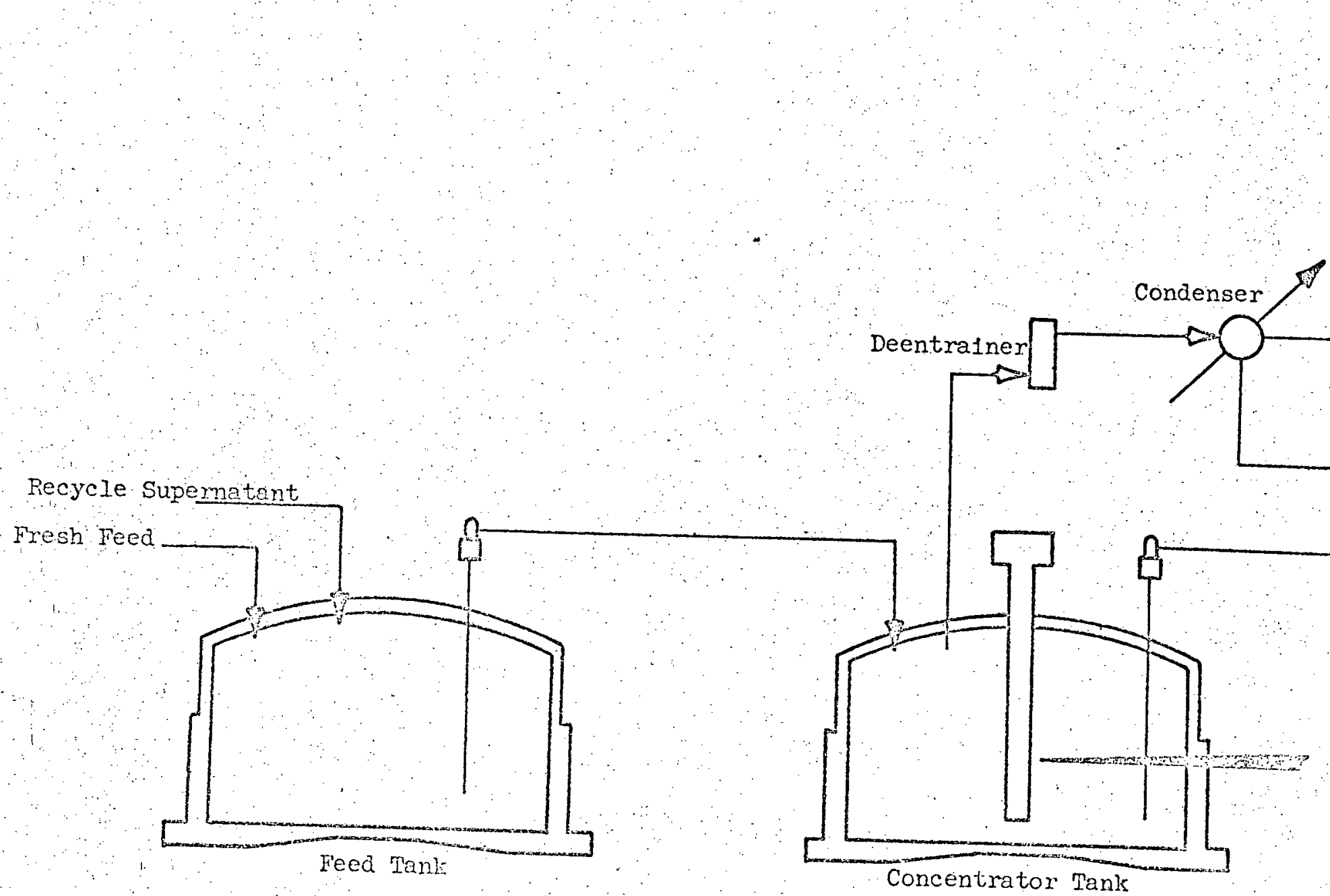

Feed Tanl:

Concentrator Tank

Electile Trmersion Heater 
FIGURE V

BEATER ELFGEIT
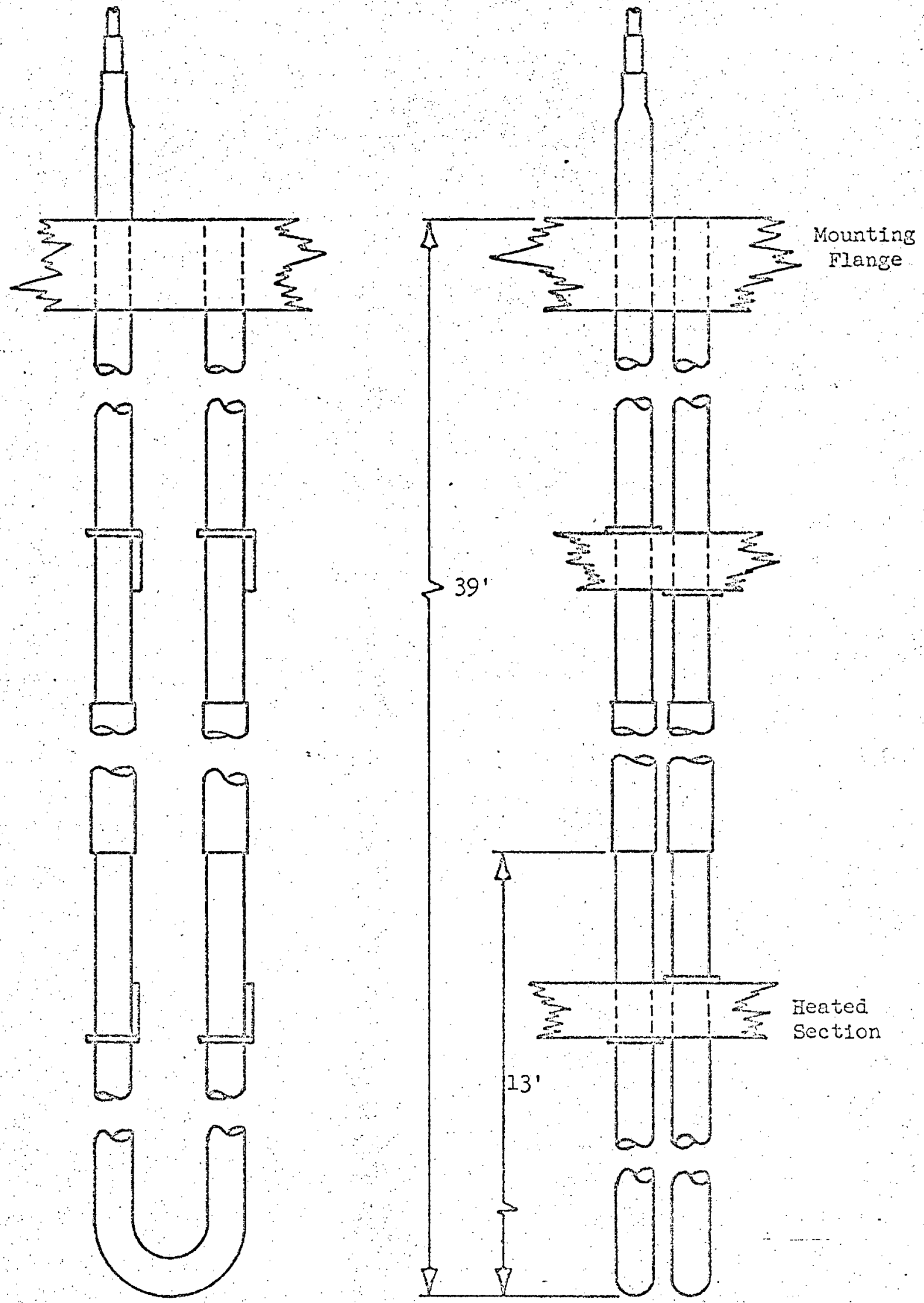
diameter airlift circulator that generates high liquid flow rates past the heater elements which retards fouling and increases heat transfer coefficients.

Heat transfer scale formation is retarded, but elements do foul occasionally. The scale readily dissolves in water, however, and the heater quadrants are cleaned by removing them from the concentrator tank and allowing them to soak for a few days in a cleaning tank filled with water. Figure VI shows a heater quadrant being removed from the cleaning tank and Figure VII. shows a quadrant being installed in the concentrator tank.

The evaporator was initially started up in December, 1967, and operated without incident until July, 1968, when heater element bumout problems developed. The burn-out failures were identified to be a combination of manufacturing anomalies, operating conditions, and electrical characteristics peculiar to floating delta electrical systems. Ground fault detection equipment was installed that disconnects the heaters when a ground fault current develops which is equivalent to $I / 10$ the normal current rating of a single element. Fuses were also installed on both legs of each element to limit current flow to 110 percent of the element's rated capacity. Operation since the addition of the protective equipment has shown that the modifications have been successful in preventing adiitional failures. 


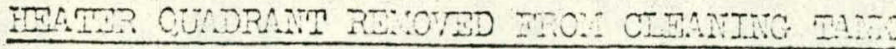

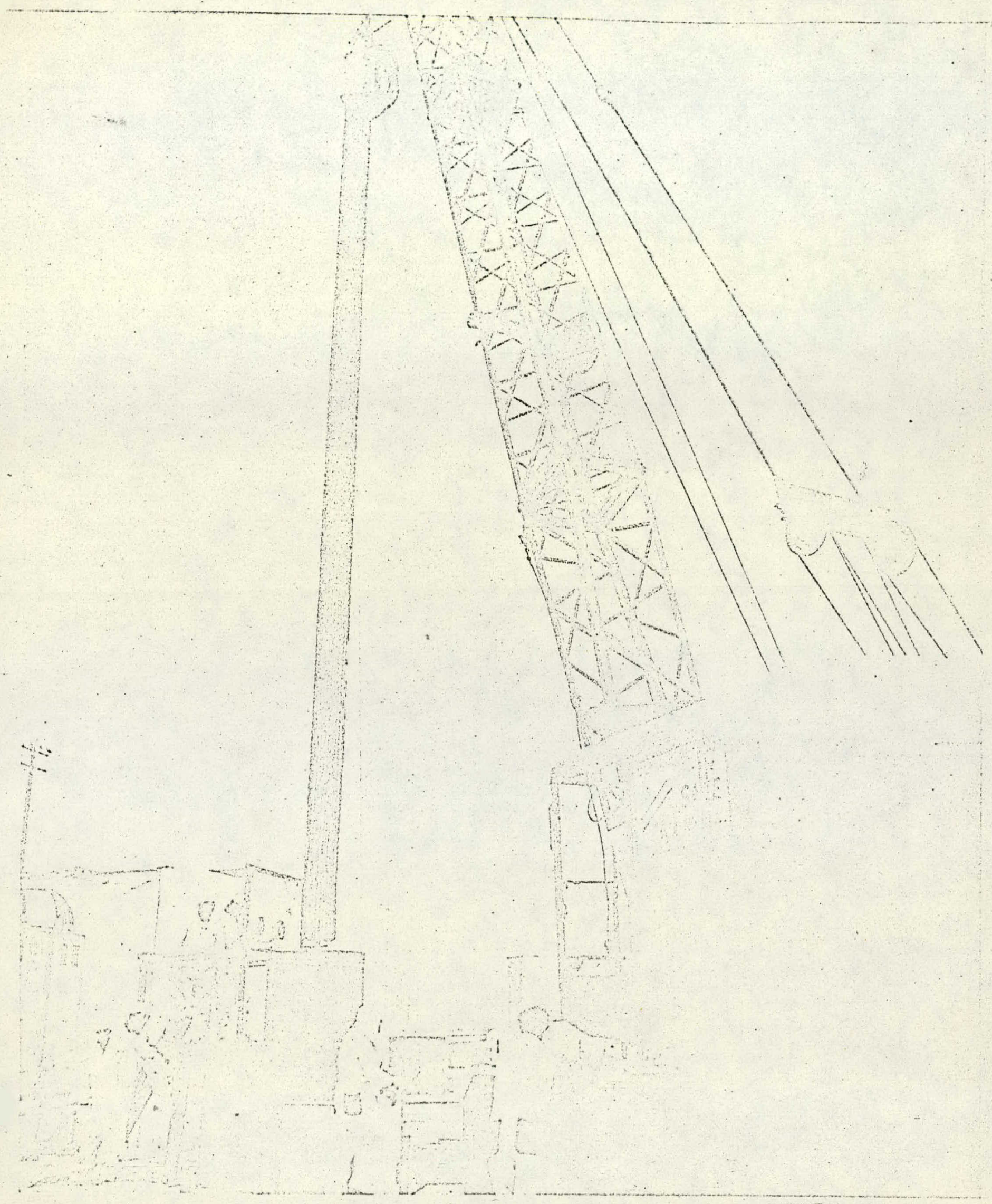


FIGUES VII

ARIT-SA-25

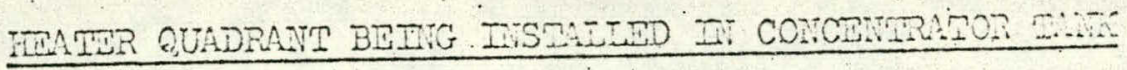

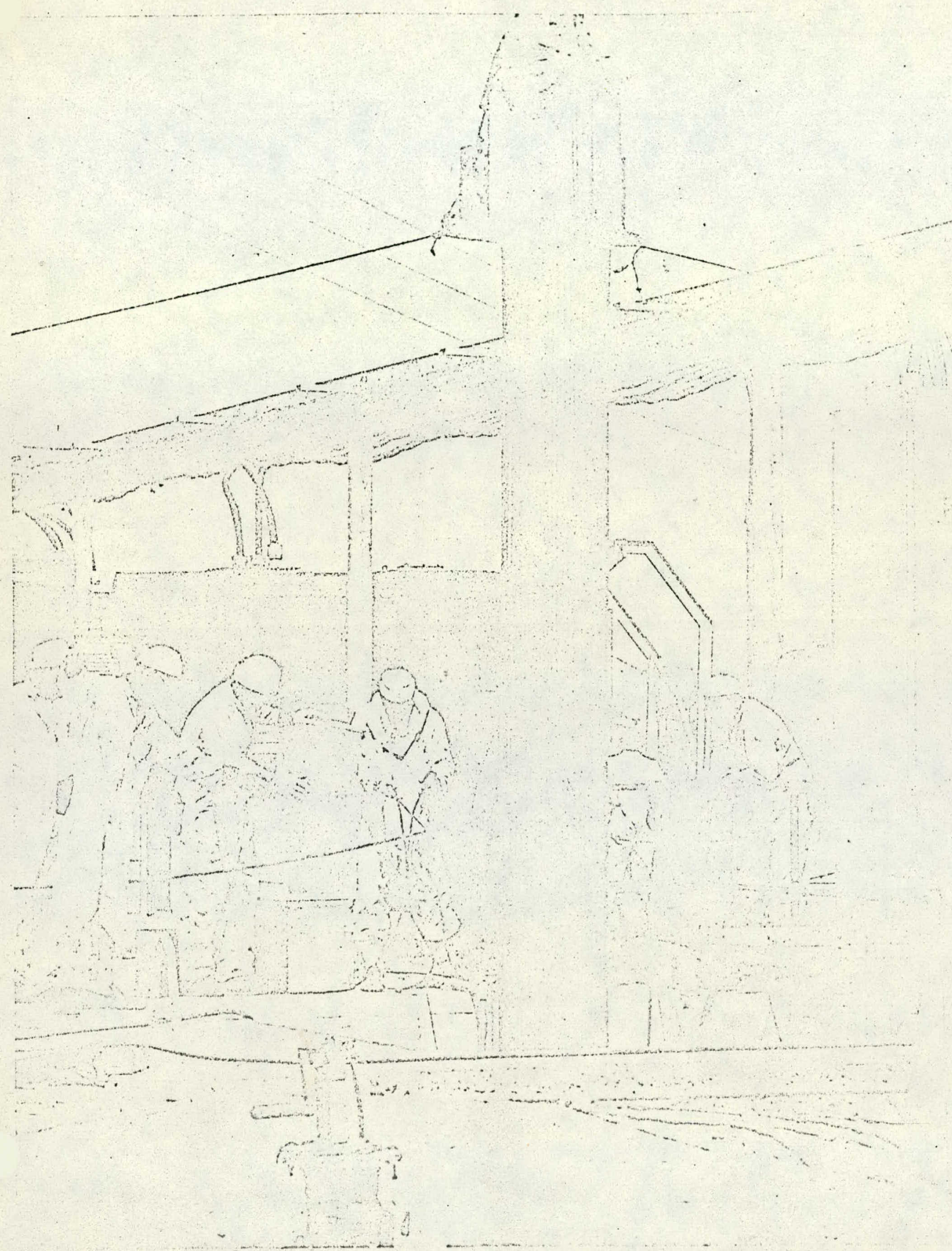


Since the electric immersion heater facility was started up in December of 1967, approximately 6 milizion galions of water have been evaporated and one million gallons of salt cake have been produced.

\section{REFERENCES}

1. Shefcik, J.J., "Operating Experience on In-Tank Solidification"; Proceedings of Symposium on Solidification and Long-Term Storage of Highly Radioactive Wastes. USAEC Document CONF-660208, pp. 787 - 797 .

2. Rey, G., "Entrainment from a Submerged Combustion Evaporator", Master of Science Thesis, University of Idaho. June, 1959.

3. Francis, C.J. and W.C. Schmidt, "Cesium Removal from a Saturated Air Stream". Paper presented at the 66th National Meeting of the American Institute of Chemical Engineers, Portland, Oregon, 1969. 